\title{
Phototreatment of Palm Oil Mill Effluent (POME) over $\mathrm{Cu} / \mathrm{TiO}_{2}$ Photocatalyst
}

\author{
Kim Hoong Ng, Mohd. Rizauddin Deraman, Chun How Ang, Soo Kee Chong, Zi \\ Ying Kong, Maksudur R. Khan, Chin Kui Cheng* \\ Faculty of Chemical \& Natural Resources Engineering, Universiti Malaysia Pahang, Lebuhraya \\ Tun Razak, 26300 Gambang, Kuantan, Pahang, Malaysia
}

Received: 5th January 2014; Revised: 8th April 2014; Accepted: 8th April 2014

\section{Abstract}

The current work reported on the use of different formulations of $\mathrm{Cu} / \mathrm{TiO}_{2}$ photocatalysts for the UVirradiation of palm oil mills effluent (POME). Different copper loadings, viz. $2 \mathrm{wt} \%, 5 \mathrm{wt} \%, 10 \mathrm{wt} \%, 15$ $\mathrm{wt} \%, 20 \mathrm{wt} \%$ and $25 \mathrm{wt} \%$ were doped onto titania. XRD pattern confirmed the presence of anatase $\mathrm{TiO}_{2}$ as primary phase due to mild calcination temperature $(573 \mathrm{~K})$. Photo-decomposition of POME over 20 wt $\% \mathrm{Cu} / \mathrm{TiO}_{2}$ exhibited the highest conversion $(27.0 \%)$ attributed to its large pore diameter $(20.0 \mathrm{~nm})$. In addition, optimum loading was $0.83 \mathrm{~g} / \mathrm{l}$. (c) 2014 BCREC UNDIP. All rights reserved

Keywords: POME; Copper; $\mathrm{TiO}_{2}$; UV-irradiation

How to Cite: Hoong, N.K., Deraman, M.R., Ang, C.H., Chong, S.K., Kong, Z.Y., Khan, M.R., Cheng, C.K., (2014). Phototreatment of Palm Oil Mill Effluent (POME) over $\mathrm{Cu} \mathrm{TiO}_{2}$ Photocatalyst. Bulletin of Chemical Reaction Engineering \& Catalysis, 9 (2): 121-127. (doi:10.9767/bcrec.9.2.6011.121-127)

Permalink/DOI: http://dx.doi.org/10.9767/bcrec.9.2.6011.121-127

\section{Introduction}

Malaysia is ranked as one of the largest palm oil producers in the world and generated at least 44 million tones of POME in the year 2008 [1]. Direct discharge of POME to rivers is disastrous to the environment due to its high biochemical oxygen demand (BOD) and chemical oxygen demand (COD) [2] Therefore, POME normally has to undergo a series of treatments before discharge. However, the conventional open-pond treatment currently used in Malaysia is land-intensive, has long hydraulic retention time (HRT) besides releasing undesirable biogas to the environment [3]. Various treatment and disposal methods have been proposed, investigated and commercialized to re-

* Corresponding Author.

E-mail: chinkui@ump.edu.my (C.K. Cheng) duce POME pollution. However, an ideal treatment process should be cost effective and most importantly, the process should not leave any hazardous residues or at least has to reduce the harmful materials to a safe level.

In the past two decades, photocatalysis process has been touted as one of the most effective clean technology for waste water treatment via removal of organic contaminants [4-6]. During the photoreaction, the catalyst will absorb the UV or visible light-energy from the light-source and attract electrons across the energy gap into the conduction band. This electron will produce hydroxyl radicals which can decompose organic compounds [4]. Hence, the adoption of photocatalysis for POME waste treatment is real especially once the technology has become mature.

According to Fujishima et al. [4], $\mathrm{TiO}_{2}$ is an excellent photocatalyst material for environ- 
mental purification. Hence, for the current work, the catalyst used was $\mathrm{Cu} / \mathrm{TiO}_{2}$ as this type of catalyst has been claimed as effective [7-9]. Thus, the objective of this study was to undertake systematic analyses into the effects of various photocatalyst formulations towards physicochemical properties and its POMEphotodegradation ability. $\mathrm{Cu}$ of loadings of 2 wt $\%, 5$ wt $\%, 10$ wt\%, 15 wt\%, $20 \mathrm{wt} \%$ and 25 wt\% were prepared using wet-impregnation method. Physicochemical properties of the prepared catalysts were determined via several well-established techniques viz. XRD, XRF, BET and TGA. Finally the effectiveness of catalysts were determined by conducting photoreactions. The COD value of POME samples were analysed before and post reaction.

\section{Materials and Methods}

\subsection{Materials}

\subsubsection{Gases}

The gases used in the current study were $\mathrm{N}_{2}$ and $\mathrm{He}$ of high purity grade (>99.996\%) and were supplied by MOX. Both gases were employed for liquid $\mathrm{N}_{2}$ physisorption analysis.

\subsubsection{Chemicals}

Table 1 shows the chemicals used. Degussa $\mathrm{P} 25-\mathrm{TiO}_{2}$ and $\mathrm{Cu}\left(\mathrm{NO}_{3}\right)_{2} \cdot 3 \mathrm{H}_{2} \mathrm{O}$ were procured from Sigma-Aldrich. The distilled water was available from the water purification system available in the laboratory of Universiti Malaysia Pahang (UMP) while POME sample was collected from the Felda Lepar Hilir 3.

\subsubsection{Catalyst Preparation}

Degussa $\mathrm{P}_{25}-\mathrm{TiO}_{2}$ photocatalyst containing predominantly anatase phase and having a specific surface area of $50 \mathrm{~m}^{2} / \mathrm{g}$ was sourced from Sigma-Aldrich. The metal dopant precursor, copper nitrate trihydrate, $\mathrm{Cu}\left(\mathrm{NO}_{3}\right)_{2} .3 \mathrm{H}_{2} \mathrm{O}$ (Sigma-Aldrich, $>98 \%$ purity), was diluted with distilled water to the concentration of $2 \mathrm{wt} \%$ in a beaker. The accurately-weighed $\mathrm{TiO}_{2}$ was added to the $2 \mathrm{wt} \%$ copper nitrate solution that has been prepared in prior and the resulting slurry was magnetic-stirred for $1 \mathrm{~h}$. Subsequently, the slurry-containing beaker was evaporated at $353 \mathrm{~K}$ using a water-bath to allow the precursor deposition onto the base $\mathrm{TiO}_{2}$. Finally, the solid material was oven-dried at $393 \mathrm{~K}$ for overnight and then air-calcined at $573 \mathrm{~K}$ for $30 \mathrm{~min}$. Preparation of other metal loadings, viz. $5 \mathrm{wt} \%, 10 \mathrm{wt} \%, 15 \mathrm{wt} \%, 20 \mathrm{wt} \%$ and $25 \mathrm{wt} \%$ of copper metal followed the same outlined procedures.

\subsection{Catalyst characterization}

Catalyst characterization provides useful information on the physicochemical attributes of the catalyst. This section describes the fundamental concepts of various characterization techniques employed for this study. Firstly, Xray fluorescence (XRF) was employed to determine the actual compositions of the catalysts prepared by using model of S8 Tiger from Bruker Cooperation. Besides, X-ray diffraction was carried out on a Philips X' Pert system using $\mathrm{CuKa}(\lambda=1.542 \AA)$ at $30 \mathrm{kV}$ and $15 \mathrm{~mA}$ for the identification of structure, crystalline phases, and also sizes of crystallites. Moreover, the density of the prepared catalysts was measured using AccuPyc II 1340 gas pycnometer from Micromeritics. In addition, liquid $\mathrm{N}_{2}$ physisorption analysis was also conducted via Autosorb-1 from Quantachrome Instruments to determine the surface area of the pretreated catalyst in the liquid nitrogen with crosssectional area of $16.2 \AA^{2}$ and temperature of 77 $\mathrm{K}$ with the help of the Autosorb software, AS1 WIN. This software offers the capability of using either branch of the isotherm for the pore size distribution calculation. Finally, thermogravimetric analysis (TGA) was also performed in an oxidative atmosphere (air) with the ramping rate of $5 \mathrm{~K} / \mathrm{min}$ for all the prepared catalysts using Q500-model thermogravimetry analyzer (TGA) to determine the thermal stability of the catalysts prepared.

Table 1. List of chemicals

\begin{tabular}{lcc}
\hline \multicolumn{1}{c}{ Chemical } & Purity & Application \\
\hline Degussa $\mathrm{P} 25-\mathrm{TiO}_{2}$ & $80 \%$ anatase, $20 \%$ rutile & catalyst preparation \\
$\mathrm{Cu}\left(\mathrm{NO}_{3}\right)_{2} .3 \mathrm{H}_{2} \mathrm{O}$ & $>98 \%$ & catalyst preparation \\
Distilled water & $100 \%$ & catalyst preparation, photoreaction \\
POME & - & Photoreaction \\
\hline
\end{tabular}




\subsection{Photoreaction}

Photoreaction of POME was carried out in a 500-ml pyrex quartz reactor. Transient photodegradation of POME samples was determined via COD analysis. The chemical oxygen demand (COD) of the original POME sample was analyzed using Hach DRB200 COD reactor before each reaction. Thereafter, $300 \mathrm{ml}$ of POME and $0.25 \mathrm{~g}$ of 2 wt $\% \mathrm{Cu} / \mathrm{TiO}_{2}$ catalyst was mixed in-situ and rigorously stirred for $2 \mathrm{~h}$ for adsorption equilibirum. Subsequently, UV lamp (1000 W) was switched on to initiate the reaction. Aliquot $3 \mathrm{ml}$ of POME sample was drawn out from the reactor every 15 min-interval for COD measurements. The COD reduction achieved was recorded. The experiment with catalyst of other metal loadings, viz. $5 \mathrm{wt} \%, 10 \mathrm{wt} \%, 15$ wt $\%, 20$ wt\% and 25 wt $\%$ of copper metal followed the same outlined procedures.

\section{Results and Discussion}

\subsection{Catalyst Characterization}

The actual percentage of $\mathrm{Cu}$ and $\mathrm{TiO}_{2}$ was obtained from XRF analysis and presented in the Table 2. The deviations were ranged from $11 \%$ to $22 \%$. The catalyst formulation that has

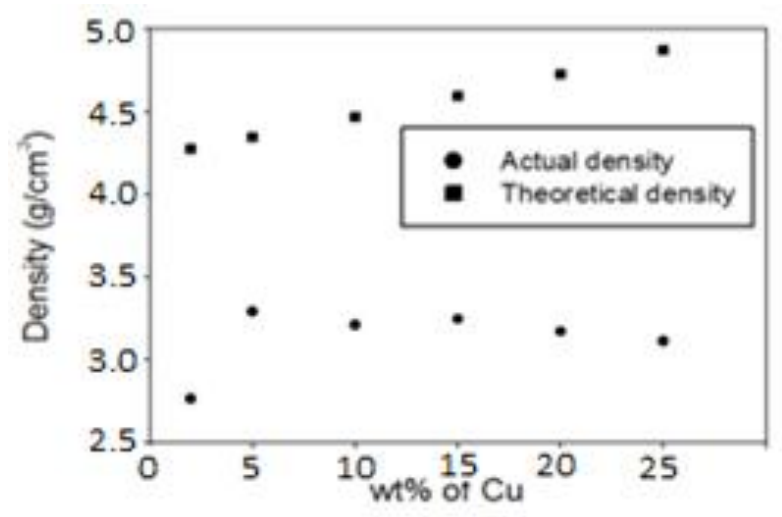

Figure 1. Comparisons of actual and theoretical density of the catalysts prepared highest deviation was $2 \mathrm{wt} \% \mathrm{Cu} / \mathrm{TiO}_{2}$ which recorded $22 \%$ deviation from the desired wt $\%$ while $25 \mathrm{wt} \% \mathrm{Cu} / \mathrm{TiO}_{2}$ exhibited least deviation from the desired wt $\%$ which was only $11 \%$.

From the XRD diffraction pattern, $\mathrm{Cu}$ peaks were observed near $2 \theta=12.9^{\circ}$ and increasing with the desired wt\% of $\mathrm{Cu}$, which confirmed the findings of XRF. Besides, $\mathrm{CuO}$ crystalline structure was discovered near $2 \theta=36.7^{\circ}$ with the size ranged from 41.8 to $49.1 \mathrm{~nm}$. Besides, from the results obtained from gas pycnometer, the measured density for all the prepared catalysts have deviated from theoretical density calculated [10]. Figure 1 shows the difference between measured density and theoretical density.

The deviations of the measured density were due to their porous structure. This is consistent with the subsequent findings from liquid $\mathrm{N}_{2}$ physisorption. Besides, liquid $\mathrm{N}_{2}$ physisorption also revealed that the surface area was decreasing with $\mathrm{wt} \%$ of $\mathrm{Cu}$ contained in catalysts. This is due to the formation of $\mathrm{CuO}$ crystal upon calcination which has blocked the pores of $\mathrm{TiO}_{2}$ support. In term of specific volume, $5 \mathrm{wt} \%$ of $\mathrm{Cu} / \mathrm{TiO}_{2}$ seems to have the largest adsorption and desorption volume, which were 0.049 and $0.0496 \mathrm{~cm}^{3} / \mathrm{g}$ respectively. Significantly, the pore volume for both adsorption and desorption decreased in the order of $10 \mathrm{wt} \%>15 \mathrm{wt} \%>2$ wt $\%>20$ wt $\%>25$ wt $\%$. In addition, Table 3 presents the pore diameter for the catalysts. It can be seen that the catalysts can be considered as mesoporous as all the pore diameters are fallen into the range of mesoporous material $(2-50 \mathrm{~nm})$. The thermal decomposition profile was obtained from TGA study as shown in Figure 2. From Figure 2, one peak was observed for each of the catalysts (besides $2 \mathrm{wt} \%$ ) at the range of 460 to $540 \mathrm{~K}$ symptomatic of the thermal decomposition of copper nitrate to $\mathrm{CuO}$. The derivative weight profile for mass loss area from $\mathrm{T}=460$ to $540 \mathrm{~K}$ were amplified and plotted in Figure 3. Peak for $2 \mathrm{wt} \%$ $\mathrm{Cu} / \mathrm{TiO}_{2}$ was undetectable probably due to low

Table 2. Results obtained from XRF test

\begin{tabular}{lcc}
\hline \multicolumn{1}{c}{ Catalyst } & Actual wt\% of $\mathbf{T i O}_{\mathbf{2}}$ & Actual wt\% of $\mathbf{~} \mathbf{~ u}$ \\
\hline $2 \mathrm{wt} \% \mathrm{Cu} / \mathrm{TiO}_{2}$ & 92.79 & 2.45 \\
$5 \mathrm{wt} \% \mathrm{Cu} / \mathrm{TiO}_{2}$ & 88.78 & 5.65 \\
$10 \mathrm{wt} \% \mathrm{Cu} / \mathrm{TiO}_{2}$ & 83.02 & 11.29 \\
$15 \mathrm{wt} \% \mathrm{Cu} / \mathrm{TiO}_{2}$ & 76.77 & 17.97 \\
$20 \mathrm{wt} \% \mathrm{Cu} / \mathrm{TiO}_{2}$ & 70.23 & 22.88 \\
$25 \mathrm{wt} \% \mathrm{Cu} / \mathrm{TiO}_{2}$ & 62.86 & 27.77 \\
\hline
\end{tabular}




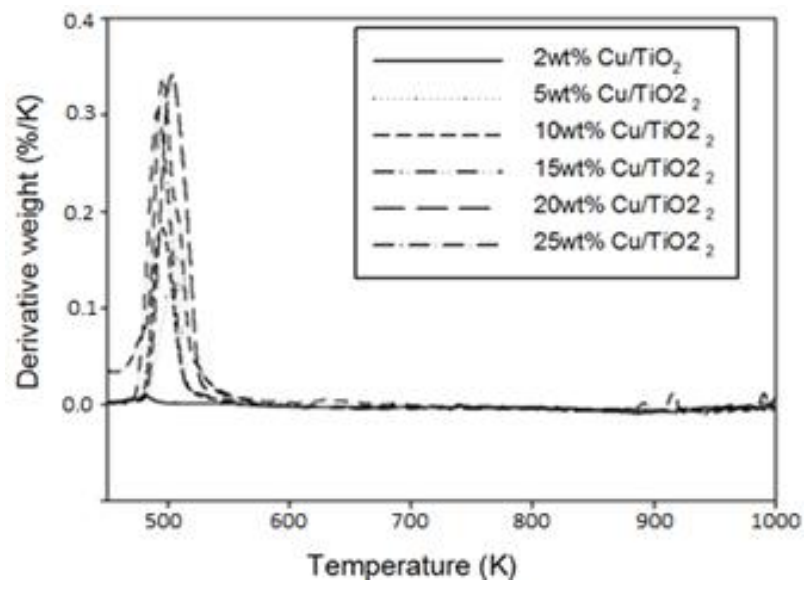

Figure 2. Complete isotherms obtained from TGA

Table 3. The pore diameters for different catalysts

\begin{tabular}{ccc}
\hline \multirow{2}{*}{ Wt\% of $\mathrm{Cu} / \mathrm{TiO}_{2}$} & \multicolumn{2}{c}{ Pore diameter $(\mathrm{nm})$} \\
\cline { 2 - 3 } & Adsorption & Desorption \\
\hline 2 & 13.90 & 13.85 \\
5 & 20.69 & 19.83 \\
10 & 19.67 & 17.47 \\
15 & 17.93 & 17.63 \\
20 & 23.39 & 19.76 \\
25 & 23.38 & 13.79 \\
\hline
\end{tabular}

$\mathrm{Cu}$ content. This was confirmed by the findings of XRD as in the preceding discussion. Based on Figure 3, the maximum peak temperatures seem to be invariant with the $\mathrm{Cu}$ loading. However, it can be observed that the intensity of the peaks increased with the wt\% of $\mathrm{Cu}$, which indicating higher content of copper nitrate present in the particular catalyst.

\subsection{Decomposition of POME}

Aliquot $3 \mathrm{ml}$ of POME samples was withdrawn every 15 min intervals for $1 \mathrm{~h}$ and analysed using COD. The obtained results are presented in Table 4. Over the entire photoreaction, the composition reading from COD showed decreasing trend.

Table 5 shows the conversion for each of the catalysts. The conversion value was computed using Equation 1:

$\mathrm{X}=\frac{\mathrm{COD}_{\mathrm{i}}-\mathrm{COD}_{\mathrm{f}}}{\mathrm{COD}_{\mathrm{i}}}$

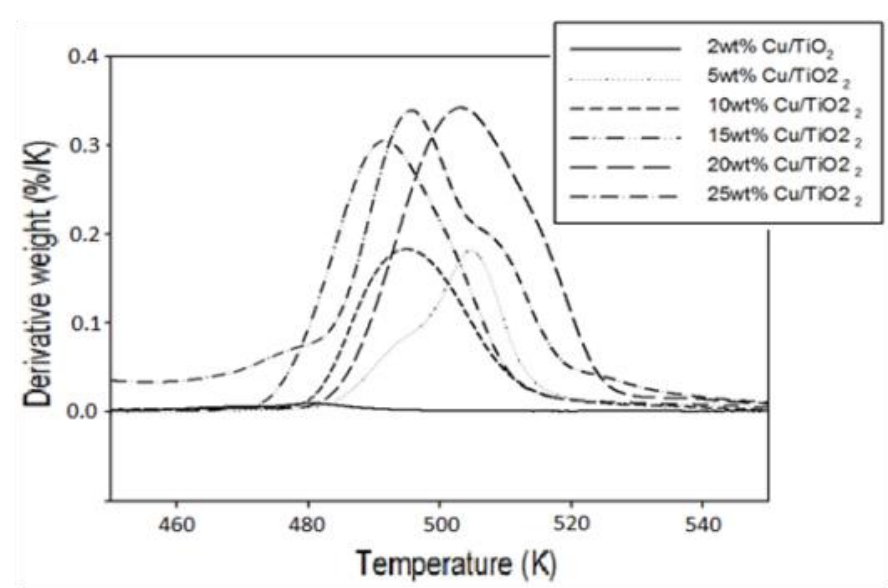

Figure 3. Isotherms ranged from 460 to $540 \mathrm{~K}$

Table 5. The conversion achieved after $1 \mathrm{~h}$ photoreaction

\begin{tabular}{cc}
\hline Wt\% of catalyst & Conversion, $\mathrm{X}$ \\
\hline 2 & 0.1422 \\
5 & 0.1727 \\
10 & 0.1869 \\
15 & 0.1992 \\
20 & 0.2700 \\
25 & 0.2096 \\
\hline
\end{tabular}

where $\mathrm{COD}_{\mathrm{i}}$ represents the initial concentration whilst $\mathrm{COD}_{\mathrm{f}}$ is the transient conversion. Highest conversion was achieved by $20 \mathrm{wt} \%$ $\mathrm{Cu} / \mathrm{TiO}_{2}$, which was $27 \%$ of the initial organics decomposed within $1 \mathrm{~h}$.

Figure 4 shows the conversion of POME and the XRF results for $2 \mathrm{wt} \%$ to $20 \mathrm{wt} \%$ of $\mathrm{Cu} / \mathrm{TiO}_{2}$. According to the conversion trend, for the $\mathrm{Cu}$ content lower than $20 \%$, the conversion was increasing with the $\mathrm{Cu}$ content. This can be explained by the higher composition of $\mathrm{Cu}$ that has widen the energy band gap of the catalysts for electron excitation and eventually enhancing the reactivity of the catalysts as well as the conversion of the POME samples. However, beyond $20 \mathrm{wt} \% \mathrm{Cu} / \mathrm{TiO}_{2}$, higher wt $\%$ of $\mathrm{Cu}$ seems to be non-effective towards reactivity of catalysts. Figure 5 shows the relationship between conversion of POME with pore diameter for $20 \mathrm{wt} \%$ and $25 \mathrm{wt} \%$ of $\mathrm{Cu} / \mathrm{TiO}_{2}$. Based on the results obtained, the conversion profile dropped gradually beyond $20 \mathrm{wt} \%$ of $\mathrm{Cu} / \mathrm{TiO}_{2}$ and this may be due to pore diameter. As 
Table 4. The COD results obtained for POME samples

\begin{tabular}{ccccccc}
\hline \multirow{2}{*}{ Time (min) } & \multicolumn{6}{c}{ COD (ppm) } \\
\cline { 2 - 7 } & 2 wt\% & 5 wt\% & 10 wt\% & 15 wt\% & 20 wt\% & 25 wt\% \\
\hline 0 & 232 & 220 & 214 & 256 & 237 & 229 \\
15 & 228 & 188 & 208 & 204 & 210 & 215 \\
30 & 226 & 192 & 196 & 212 & 178 & 214 \\
45 & 199 & 186 & 194 & 209 & 179 & 187 \\
60 & 199 & 182 & 174 & 205 & 173 & 181 \\
\hline
\end{tabular}

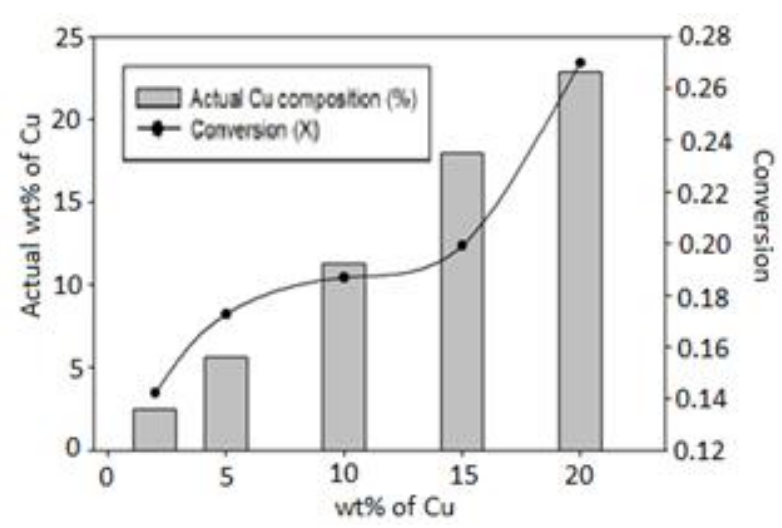

Figure 4. The relationship of conversion with the actual composition of $\mathrm{Cu}$ for 2 to $20 \mathrm{wt} \%$ of $\mathrm{Cu} / \mathrm{TiO}_{2}$

shown in Table 3, the small desorption pore diameter of $25 \mathrm{wt} \% \mathrm{Cu} / \mathrm{TiO}_{2}$ has probably inhibit the accessibility of the substrate in POME and eventually limited the catalyst reactivity and POME conversion.

\subsection{Kinetic Modelling}

The decomposition rate of organics in POME was described by the power-law model given in Equation 2:

$$
-\mathrm{r}_{\mathrm{o}}=\mathrm{kC}_{\mathrm{A}}^{\alpha}
$$

where $\left(-r_{0}\right)$ is the rate of organics decompose $(\mathrm{ppm} / \mathrm{min}), \mathrm{k}$ is the specific reaction rate $(\mathrm{ppm} / \mathrm{min}) ; \mathrm{C}_{\mathrm{A}}$ is the concentration of organics in POME (ppm) and $\alpha$ is the order of the reaction. The data from Table 4 were analyzed using integral method [11] to determine the reaction order. In the current work, several orders of reaction were tested such as $1^{\text {st }}, 2^{\text {nd }}$ and $3^{\text {rd }}$. Upon comparison, it was found that the $2^{\text {nd }}$ order fitting seems to give the best fit with the decomposition rate. The results are shown in Figure 6.

The adequacy of power-law model for extracting essential information from organics de-

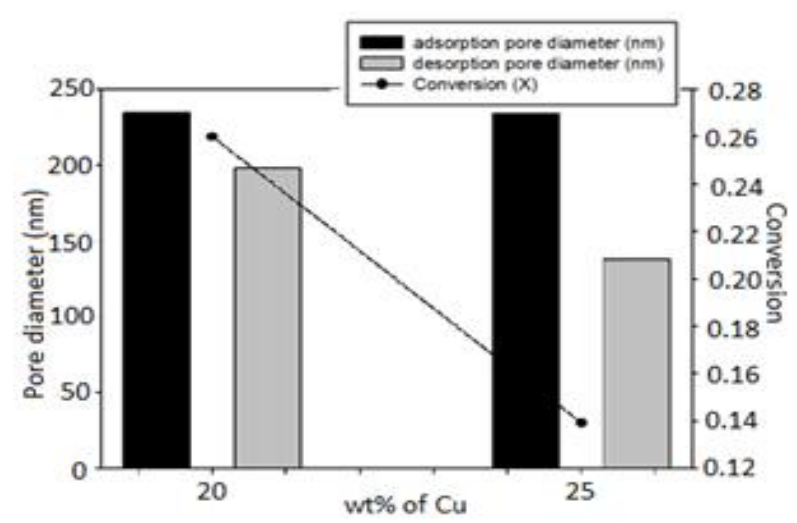

Figure 5. The relationship of conversion with the pore diameters for $20 \mathrm{wt} \%$ and $25 \mathrm{wt} \%$ of $\mathrm{Cu} / \mathrm{TiO}_{2}$

composition data was appraised by a rigorous error analysis. Figure 7 shows a parity plot suggesting a fairly good agreement between predicted $\left(1 / C_{A}\right)$ value and observed $\left(1 / C_{A}\right)$ value from Table 4 with $R^{2}$-value of 0.91 . Additionally, as the residual plot depicted in Figure 8 evinces no obvious pattern, hence it can be concluded that power-law model is sufficient [12] to represent the current data.

Moreover, the specific reaction constant $(k)$ obtained were different for each catalysts. The slopes of these data $(k)$ were calculated and tabulated in Table 6 .

Based on Table 6 , these obtained $k$-values reasonably shows a trend with optimum at 20 wt\% of $\mathrm{Cu}$, which was consistent with the $\mathrm{Cu}$ composition and pore diameter discussed earlier that lead to higher conversion. The $k$ for 20 wt\% $\mathrm{Cu} / \mathrm{TiO}_{2}$ (2.6016) was higher than $25 \mathrm{wt} \%$ (1.9301), 10 wt\% (1.7904), 15 wt\% (1.6197), 5 wt\% (1.5815) and lastly $2 \mathrm{wt} \%$ (1.1913).

\subsection{Optimum Catalyst Loading}

Three sets of photoreaction were conducted with catalyst loading of $0.5 \mathrm{~g} / \mathrm{l}, 0.83 \mathrm{~g} / \mathrm{l}$ and 1.0 $\mathrm{g} / \mathrm{l}$ to determine the optimum catalyst loading for POME photo-degradation. The catalyst cho- 


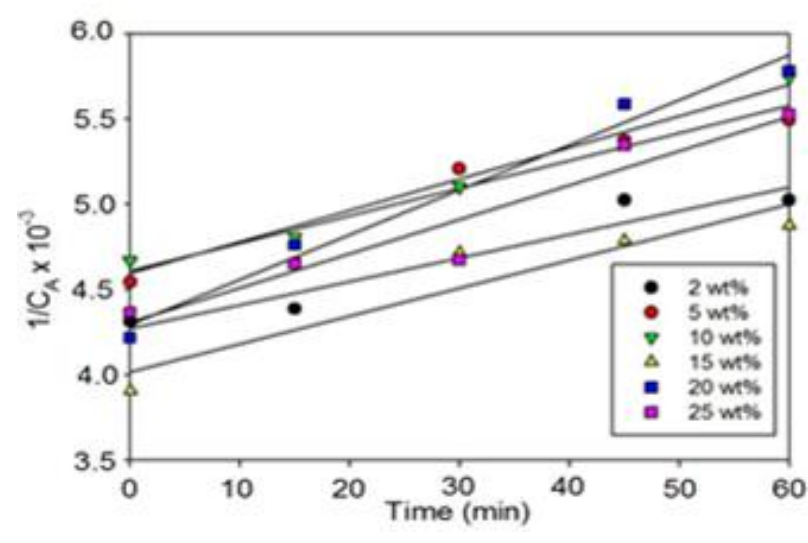

Figure 6. $2^{\text {nd }}$-order organic decomposition graph based on data in Table 4

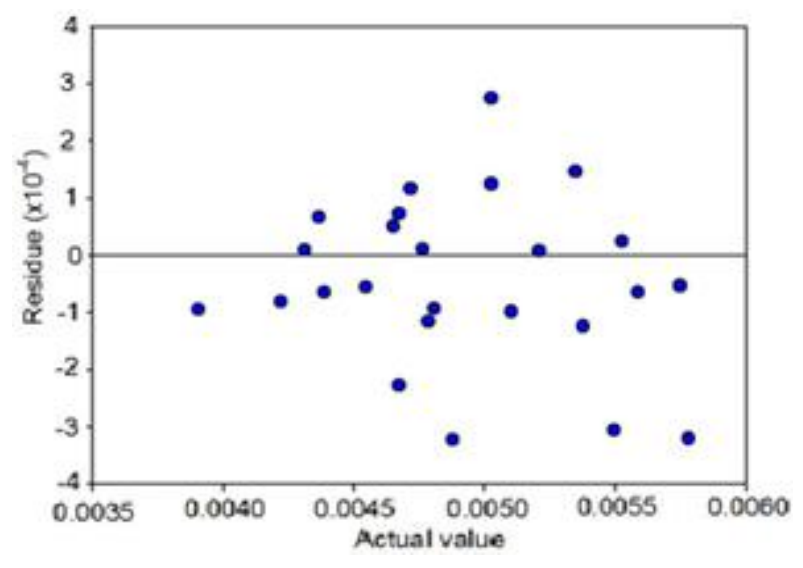

Figure 8. Residual plot for decomposition rate

sen for current set of reaction was $20 \mathrm{wt} \%$ of $\mathrm{Cu} / \mathrm{TiO}_{2}$ as it is previously proven as the optimum performer in terms of conversion. The results obtained are plotted in the Figure 9. Based on the results (cf. Figure 9), the optimum catalyst loading was $0.83 \mathrm{~g} / \mathrm{l}$. An approximately $27.0 \%$ of the organics was converted within $1 \mathrm{~h}$. Generally, higher catalyst loading indicates higher conversion of organics in POME. Thus, for catalyst loading lower than $0.83 \mathrm{~g} / \mathrm{l}$, the conversion of organics would increase with the catalyst loading. Nevertheless, beyond $0.83 \mathrm{~g} / \mathrm{L}$, reduction of organics was observed due to high catalyst loading causing formation of slurry mixture which has inhibited the penetration of UV light and eventually causing reduction in organics conversion.

\subsection{Longevity Photoreaction Study}

Previously, the catalyst with highest reactivity $\left(20 \mathrm{wt} \% \mathrm{Cu} / \mathrm{TiO}_{2}\right.$ ) and optimum catalyst loading $(0.83 \mathrm{~g} / \mathrm{l})$ were determined. A reaction was conducted with these findings to determine

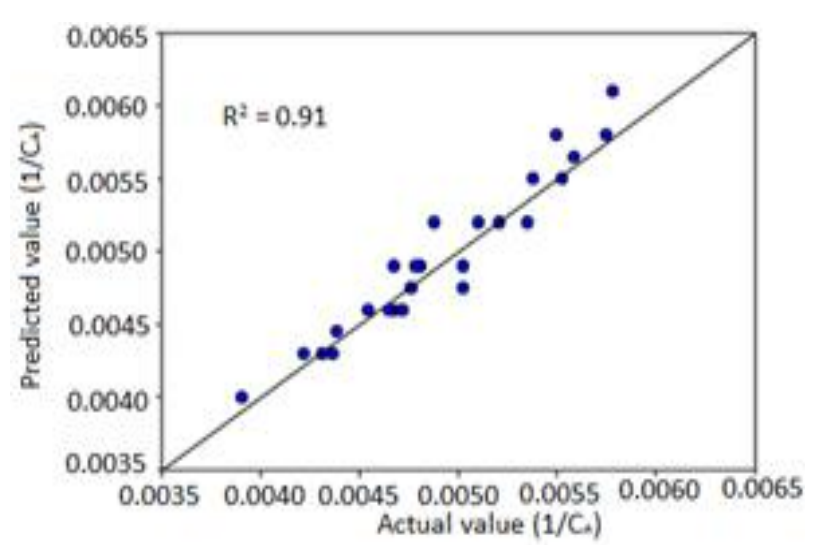

Figure 7. Comparison between predicted rate and observed rate

Table 6. The $k$-values for various catalysts

\begin{tabular}{cc}
\hline Wt\% of $\mathrm{Cu}$ & $\begin{array}{r}\text { Specific reaction constant } \times 10^{5} \\
(\mathrm{k})(\mathrm{ppm} \text { min })^{-1}\end{array}$ \\
\hline 2 & 1.1913 \\
5 & 1.5818 \\
10 & 1.7904 \\
15 & 1.6197 \\
20 & 2.6016 \\
25 & 1.9301 \\
\hline
\end{tabular}

the capability of organics decomposition within $7 \mathrm{~h}$. The POME samples were taken for every hour for COD analysis. The conversions were calculated using Equation 1 and results obtained are shown in Figure 10.

Based on COD analysis, after $7 \mathrm{~h}$ of UV radiation, more than $40 \%$ of organics in POME has been converted. As shown in Figure 10, most of the organics conversion occurred during the $1^{\text {st }} \mathrm{h}$ reaction. After that, the reaction progressively slowed down and a final conversion of $40 \%$ was achieved after $7 \mathrm{~h}$ of UV irradiation. This could be explained by the deactivation of catalyst due to solid organic deposition on the catalyst surface after the organics decomposition.

\section{Conclusions}

As a conclusion, current work has shown that POME waste can be treated via photoreaction in the presence of $\mathrm{Cu} / \mathrm{TiO}_{2}$ catalyst. By using this new proposed method, the retention time for POME treatment can be 


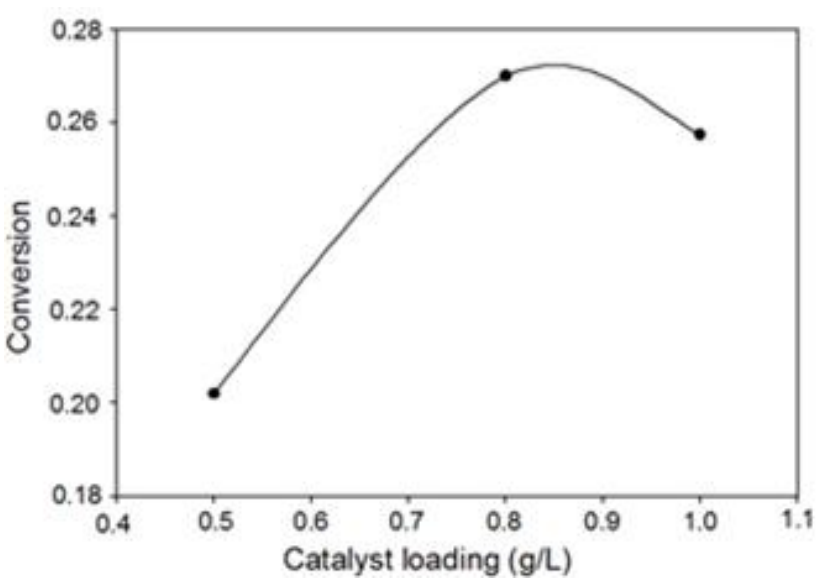

Figure 9. Graph of conversion versus catalyst loading

significantly decreased from 20 days of hydraulic rentention time to within hours. From the results, $20 \mathrm{wt} \% \mathrm{Cu} / \mathrm{TiO}_{2}$ yielded the highest organic degradability (conversion) which is $27 \%$ of organics converted within $1 \mathrm{~h}$. Besides, the optimum catalyst loading for 20 wt\% of $\mathrm{Cu} / \mathrm{TiO}_{2}$ is $0.83 \mathrm{~g} / \mathrm{l}$ and with this catalyst loading, more than $40 \%$ of the organics in POME will decompose within $7 \mathrm{~h}$.

\section{Acknowledgments}

The authors would like to thank Ministry of Education Malaysia for the Exploratory Research Grant Scheme RDU120613 and Universiti Malaysia Pahang for Short Term Grant RDU120323.

\section{References}

[1] Wu, T.Y., Mohammad, A.W., Jahim, J.M., Anuar, N. (2010). Pollution control technologies for the treatment of palm oil mill effluent (POME) through end-of-pipe processes. J. Environ. Manage., 91: 1467-1490.

[2] Ahmad, A.L., Ismail, S., Bhatia, S. (2003). Water recycling from palm oil mill effluent (POME) using membrane technology. Desalination, 157: 87-95.

[3] Vijayaraghavan, K., Ahmad, D., Abdul Aziz, M.E. (2007). Aerobic treatment of palm oilmill effluent. $J$ Environ Manage, 82: 24-31.

[4] Fujishima, A., Rao, T.N., Tryk, D.A. (2000). Titanium dioxide photocatalysis. J. Photoch. Photobio. A., 1: 1-21.

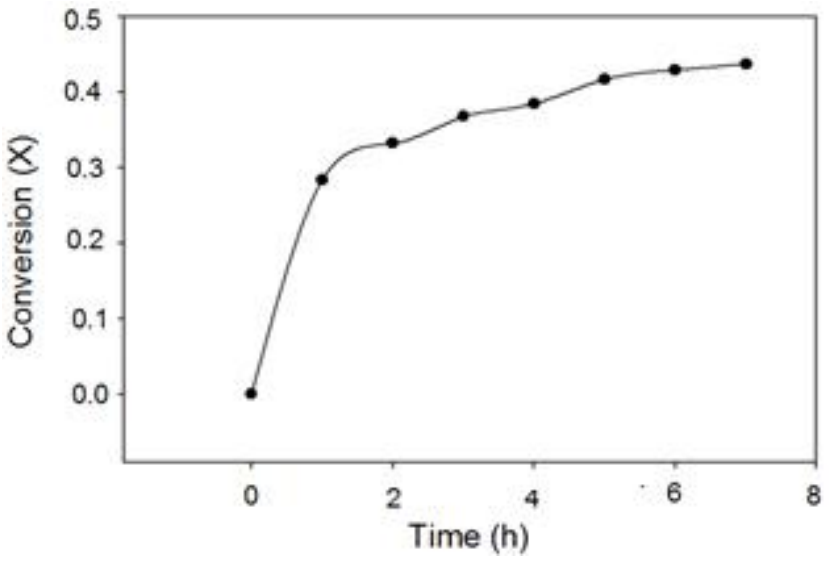

Figure 10. The conversion profile of organics in POME

[5] Bahnemann, D. (2004). Photocatalytic Water Treatment: Solar Energy Applications. Sol Energy, 77: 445-459.

[6] Puzyn, T., Mostrag-Szlichtyng, A. (2012). Organic pollutants ten years after the stockholm convention - Environmental and analytical update. Croatia: Intech.

[7] Wu, N., Lee, M. (2004). Enhanced $\mathrm{TiO}_{2}$ photocatalysis by $\mathrm{Cu}$ in hydrogen production from aqueous methanol solution. Int $J$ Hydrogen Energ, 29(15): 1601-1605.

[8] Yoong, L.S., Chong, F.K., Dutta, B.K. (2009). Development of copper-doped $\mathrm{TiO}_{2}$ photocatalyst for hydrogen production under visible light. Energy, 34(10): 1652-1661.

[9] Raiz, N., Chong, F. K., Dutta, B. K., Man, Z. B., Khan, M. S., \& Nurlaela, E. (2012). Photodegradation of Orange II under visible light using $\mathrm{Cu}-\mathrm{Ni} / \mathrm{TiO}_{2}$ : Effect of calcination temperature. Chem Eng J, 185-186: 108-119.

[10] Felder, R.M., Rousseau, R.W. (2005). Elementary Principles of Chemical Processes (3 ed.).New York: John Wiley \& Sons.

[11] Fogler, H.S. (2006). Element of Chemical Reaction Engineering (4 ed.). United Nations: Pearson Education.

[12] Montgomery, D.C. (1997). Design and Analysis of Experiment. New York: John Wiley \& Sons Inc. 